\title{
A comparison between the responses of neutral red and acridine orange: Acridine orange should be preferential and alternative to neutral red as a dye for the monitoring of contaminants by means of biological sensors
}

\author{
Sabrina Manente ${ }^{a}$, Silvia De Pieri ${ }^{a}$, Alessandra Iero ${ }^{b}$, Chiarafrancesca Rigo ${ }^{\text {, }}$, Marcantonio Bragadin ${ }^{a, *}$ \\ ${ }^{a}$ Department of Environmental Sciences, Ca' Foscari University of Venice, Dorsoduro, Venice 30123, Italy \\ ${ }^{\mathrm{b}}$ Institute of Applied Ecology, Health Science, and Design, University of Canberra, Bruce, ACT 2617, Australia
}

\section{A R T I C L E I N F O}

\section{Article history:}

Received 1 August 2008

Available online 17 September 2008

\section{Keywords:}

Acridine orange

Neutral red

In vitro toxicology

\begin{abstract}
A B S T R A C T
The acridine orange (AO) and neutral red (NR) dyes, commonly used as probes to measure the internal pH in acidic vesicles, are compared in this article. The comparison between the two dyes (arising from calculations taking into account their analytical constants) illustrated that the use of $\mathrm{AO}$ is preferential to that of NR because the $\mathrm{AO}$ response is sensitive over the whole $\mathrm{pH}$ range between 4.0 and 7.4, whereas the NR response is effective only between pHs 4.0 and 6.0. In addition, it became evident from the mitochondrial respiration response that $\mathrm{NR}$, unlike $\mathrm{AO}$, is a protonophore. When taken into consideration, these two properties suggest that $\mathrm{AO}$ is more suitable than NR as an indicator of toxicity measurements in water samples because the environmental toxic compounds induce $\mathrm{pH}$ changes in the acidic vesicles of biological structures that are used as environmental biosensors.
\end{abstract}

(ㄷ) 2008 Elsevier Inc. All rights reserved.
Many methods have been proposed for the evaluation of the presence of toxic compounds in water and to assess the risks to both humans and animals. These methods, based on the responses to toxic compounds in fish and invertebrates, are often impractical because they are expensive and time-consuming. These factors have stimulated researchers to develop more rapid and inexpensive methods of evaluation, and a wide range of alternative in vitro tests have been proposed [1-6]. One of these in vitro tests uses the response of mussels to monitor the environmental status of sea water [3,7-9].

When marine molluscs such as mussels are exposed to contaminants, one of the characteristic pathological alterations is a decreased integrity in the lysosomal membrane [10]. This loss of integrity is assayed using the dye neutral red (NR). ${ }^{1}$ The dye enters the lysosomes of the mussels and accumulates inside, with the driving force being the internal acidic pH. The damage to the lysosomes, induced by the toxic compounds, induces a release of the dye from the lysosomes to the resuspending medium. A spectrophotometric measurement of the amount of NR in the resuspending medium gives a measurement of the level of damage induced by the toxic compounds. We believe, and demonstrate in this article, that the procedure has some weak points; the acridine orange (AO) dye, which is widely used for acidic $\mathrm{pH}$ measurements in isolated

\footnotetext{
* Corresponding author. Fax: +39 0412348953.

E-mail address: bragadin@unive.it (M. Bragadin).

${ }^{1}$ Abbreviations used: NR, neutral red; AO, acridine orange; ATP, adenosine triphosphate; FCCP, trifluoromethoxy carbonyl cyanide phenylhydrazone.
}

lysosomes, offers some advantages and is preferred to measurements based on the NR response.

\section{Materials and methods}

Acid $\mathrm{pH}$ measurements using the response of the AO dye

The measurements were performed using a Jenway $6400 \mathrm{spec}-$ trophotometer under stirring at room temperature. The lysosomes, having been prepared and purified according to the classical procedure [11], were resuspended in a medium $(2.5 \mathrm{ml}$ ) (final concentration $0.2 \mathrm{mg} / \mathrm{ml}$ ). The medium composition was $0.125 \mathrm{M} \mathrm{KCl}$, $10 \mathrm{mM}$ Hepes-Mops (pH 7.4), and $5 \mathrm{mM} \mathrm{MgCl}_{2}$.

Following the addition of the AO dye $(5 \mu \mathrm{M})$, the instrument was adjusted to zero absorbance. The addition of $2 \mathrm{mM}$ adenosine triphosphate (ATP), therefore, induces an absorbance quenching at $492 \mathrm{~nm}$.

\section{Oxygen consumption experiments}

The mitochondria from rat liver were prepared following the usual procedure [12]. The mitochondrial protein content was determined using the method of Lowry and coworkers [13].

The mitochondrial oxygen consumption was measured using a Clark oxygen electrode (Yellow Springs Instruments, Yellow Springs, OH, USA fitted in a closed thermostated chamber $(2 \mathrm{ml})$ at $20^{\circ} \mathrm{C}$ equipped with magnetic stirring. The mitochondria (final 
concentration $2.5 \mathrm{mg} / \mathrm{ml}$ ) were resuspended in $2 \mathrm{ml}$ of the medium. The medium composition was $0.25 \mathrm{M}$ sucrose, $10 \mathrm{mM}$ Hepes-Mops (pH 7.4), and $1 \mathrm{mM} \mathrm{MgCl}_{2}$.

All of the reagents were of analytical grade. The succinate, AO, $\mathrm{NR}$, and $p$-trifluoromethoxy carbonyl cyanide phenylhydrazone (FCCP) were purchased from Sigma-Aldrich.

\section{Results and discussion}

The measurement of the internal $\mathrm{pH}$ in acidic vesicles is based on the responses given by dyes such as AO and NR [14-17]. Both compounds are weak bases $\left(\mathrm{p} K_{\mathrm{a}}=6.5\right.$ for NR, $\mathrm{p} K_{\mathrm{a}}=10.5$ for AO $[15,18])$. These weak bases, being permeant, cross the biological phospholipidic membranes as neutral compounds and, following the classical transport mechanism of weak permeant bases [19], accumulate in the matrix, the driving force being the internal acidic $\mathrm{pH}\left(\mathrm{pH}_{\mathrm{i}} 4.0\right.$ in Fig. 1). The accumulation in the matrix gives rise to an absorption change that is probably due to a metachromatic effect [16]. Therefore, in the case of AO, by operating at a wavelength of $492 \mathrm{~nm}$, which is the absorption maximum in water, the accumulation in an acidic matrix gives rise to a spectral change and the acidification is followed by the signal quenching that accompanies the entry of the dye. Fig. 2 shows an example of the use of AO to follow the acidification process in isolated lysosomes, where the $\mathrm{pH}$ in the matrix is approximately $4.5[11,17,19]$. Analogous responses are obtained if $\mathrm{NR}$, instead of $\mathrm{AO}$, is used [16]. The $\mathrm{AO}$ and NR dyes accumulate in the acidic compartments of the cell by means of a similar mechanism $[19,11,20]$.

This capacity of measuring the internal pH in lysosomes is used in environmental tests to monitor the quality of water samples $[7,8]$ because it is assumed that the status of the lysosomes (i.e., the $\mathrm{pH}$ in the lysosomal matrix) in the cells of the biosensors (mussels) is a measurement of the environmental contamination [7-9]. To this end, the lysosomal efficiency in mussels is measured on the basis of the accumulation (and release) of NR. The standard test [21] forecasts an incubation period of $3 \mathrm{~h}$ following the addition of the NR. A spectrophotometric determination of the concentration of NR in the supernatant gives a measurement of the status of the cells (in the mussels) because the release of NR in the supernatant is due to damage to the lysosomal membrane (and to the structures, pumps, enzymes, etc. that concur to this internal acidification) caused by toxic compounds. This results in a permeability enhancement of the membrane, an increase in the internal $\mathrm{pH}$, and a subsequent NR release. Therefore, the concentration of NR in the supernatant is assumed to be an index of the toxicity of the solution [21]. We believe that the procedure has some weak points

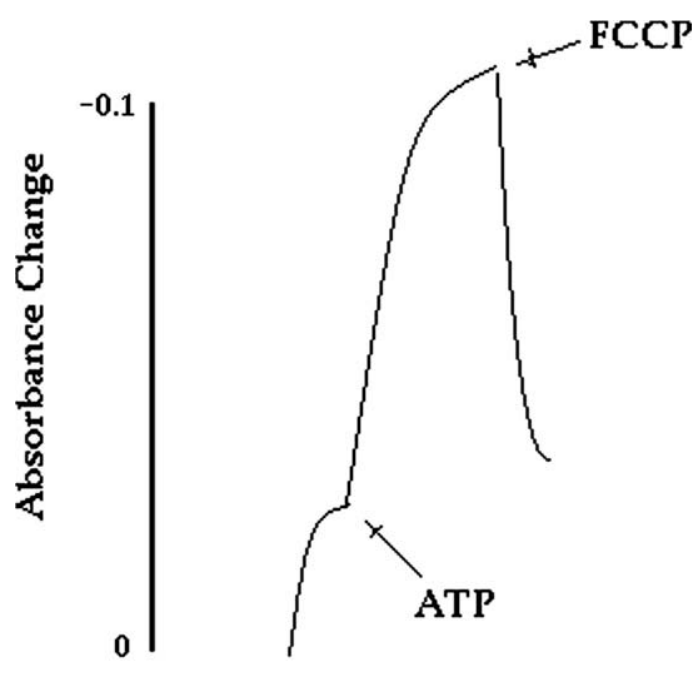

\section{$5 \mathrm{~min}$}

Fig. 2. An example of the use of $A O$ as an indicator of the internal $\mathrm{pH}$ in lysosomes. The acidic $\mathrm{pH}$ in lysosomes induces an accumulation of $\mathrm{AO}$, with a consequent signal quenching at $492 \mathrm{~nm}$ (metachromasy). The release of the dye induced by a classical protonophore such as FCCP $(100 \mathrm{nM})$ shows an example of release of the dye induced by membrane permeability enhancement and indicates that the transport of $A O$ is very fast.

and that the same type of measurements could give some advantages if they were carried out using AO instead of NR.

The accumulation ratio $R$ (i.e., the ratio between the internal and external concentration of the dye),

$R_{\mathrm{AO}}=\frac{[\mathrm{AO}]_{i}+\left[\mathrm{AOH}^{+}\right]_{i}}{[\mathrm{AO}]_{o}+\left[\mathrm{AOH}^{+}\right]_{o}}$ for $\mathrm{AO}$ and $R_{\mathrm{NR}}=\frac{[\mathrm{NR}]_{i}+\left[\mathrm{NRH}^{+}\right]_{i}}{[\mathrm{NR}]_{o}+\left[\mathrm{NRH}^{+}\right]_{o}}$ for NR,

Where

$[\mathrm{AO}]_{\mathrm{i}}$ and $[\mathrm{NR}]_{\mathrm{i}}$ are the concentrations of the AO and NR dyes in the matrix of the vesicle in undissociated form;

$[\mathrm{AO}]_{\mathrm{o}}$ and $[\mathrm{NR}]_{\mathrm{o}}$ are the concentrations of the dyes in the external medium in undissociated form;

$\left[\mathrm{AOH}^{+}\right]_{i}$ and $\left[\mathrm{NRH}^{+}\right]_{i}$ are the concentrations of $\mathrm{AO}$ and NR in protonated form in the matrix of the vesicles;

$\left[\mathrm{AOH}^{+}\right]_{\mathrm{o}}$ and $\left[\mathrm{NRH}^{+}\right]_{\mathrm{o}}$ are the concentrations of $\mathrm{AO}$ and NR as protonated forms in the external medium (see the scheme in Fig. 1),
In

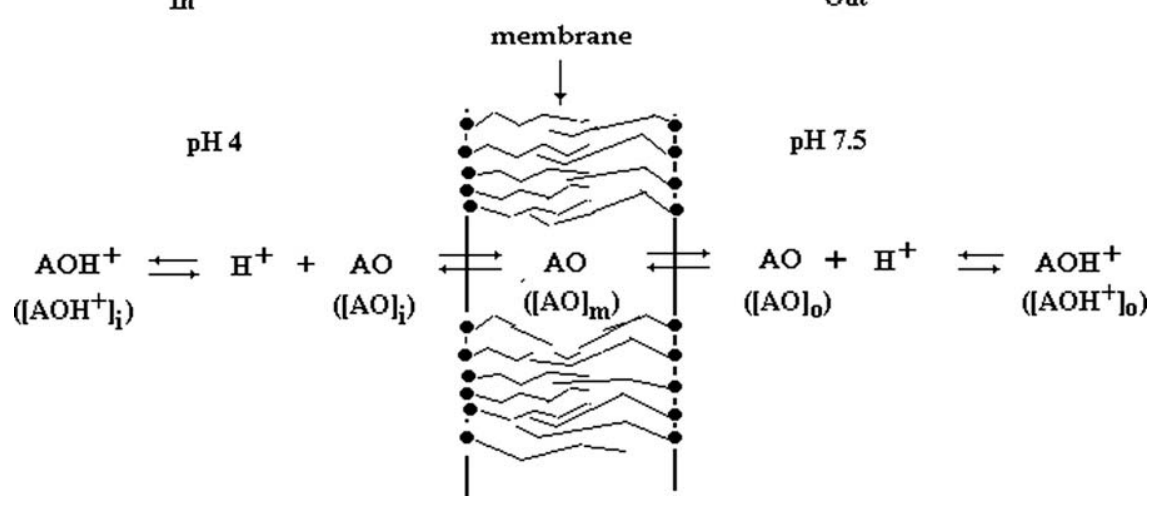

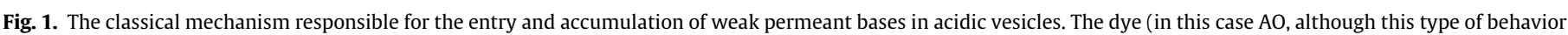

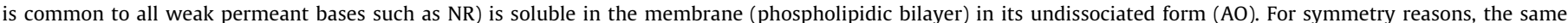

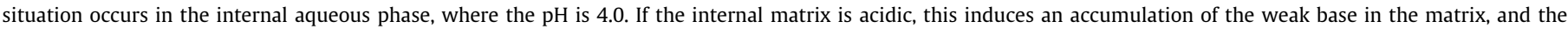
accumulation increases as the internal $\mathrm{pH}\left(\mathrm{pH}_{\mathrm{i}}\right)$ becomes more acidic. 
in acidic vesicles can easily be calculated when the $\mathrm{p} K_{\mathrm{a}}$ values for AO and RN are taken into account. Another factor is that, as a consequence of the existence of a partition coefficient,

$K=[\mathrm{AO}]_{\text {membr }} /[\mathrm{AO}]_{\text {water }}$,

where

$[\mathrm{AO}]_{\text {membr }}$ is the concentration of the soluble $\mathrm{AO}$ in the membrane;

$[\mathrm{AO}]_{\text {water }}$ is the concentration of the AO soluble in water,

and then $[A O]_{o}=[A O]_{i}$ (see Fig. 1). Analogous calculations regarding $N R$ give the same conclusion (i.e., $[N R]_{o}=[N R]_{i}$ ). The results of the calculations are summarized in Table 1.

Because the internal $\mathrm{pH}$ in the lysosomes $\left(\mathrm{pH}_{\mathrm{i}}\right)$ of the cells is modified by the presence of toxic compounds, with a consequent release of either AO or NR from the lysosomes to the resuspending medium, Table 1 reports the accumulation ratio and the concentration of the AO and NR dyes in the supernatant, calculated at different $\mathrm{pH}_{\mathrm{i}}$ values. With regard to these calculations, the $\mathrm{pH}_{\mathrm{o}}$ in the cytoplasm is 7.5.

It can be seen in Table 1 and from the corresponding graph (Fig. 3) that $\mathrm{NR}$ is sensitive to the $\mathrm{pH}_{\mathrm{i}}$ only in the $\mathrm{pH}$ values ranging from 4.0 (4.5-5.0 is the $\mathrm{pH}$ value in the matrix of lysosomes in noncontaminated cells) to 6.0. In the $\mathrm{pH}_{\mathrm{i}}$ values from 6.0 to 7.5 (which is the physiological $\mathrm{pH}$ value in the cytoplasm), the response and the release of NR in the supernatant is the same. This means that any damage to the lysosomes that induces an enhancement of the $\mathrm{pH}_{\mathrm{i}}$ from 6.0 to 7.5 gives the same response, corresponding to that given by the total destruction of the lysosomal membrane (i.e., a $\mathrm{pH}_{\mathrm{i}}$ of 7.5). Therefore, $\mathrm{NR}$ cannot be used as a probe in measurements of the $\mathrm{pH}_{\mathrm{i}}$ values that range between 6.0 and 7.5. This problem does not occur when using AO (see the graph in Fig. 3) and is due to the different $\mathrm{p} K_{\mathrm{a}}$ values of the two dyes.

There are additional advantages in choosing AO instead of NR. Both dyes are protonophores (i.e., substances that enhance the proton permeability) $[1,9,14,22]$, but AO is less protonophoric than NR. The mechanism that induces an enhancement of the proton conductivity is due to the presence of a potential in the biological membranes. With regard to lysosomes, the matrix $\mathrm{pH}$ is approximately 4.5 to 5.0 [19] due to the presence of an ATP-driven proton pump $[11,19]$. This pump drives the protons in the matrix. The latter gives rise to a positive inside potential that is only partially neutralized by the entry of $\mathrm{Cl}^{-}$ions through a selective channel [19]. In steady-state conditions, the potential is approximately $+40 \mathrm{mV}[23]$. This value is not particularly high, but it could induce an extrusion of the accumulated dye as a charged cation, thereby giving rise to a cyclic mechanism. The mechanism is called a protonophore effect because, at any cycle, a proton is extruded with a consequent $\mathrm{pH}_{\mathrm{i}}$ enhancement. Obviously, such an effect should be as minimal as possible because it is equivalent to that produced by environmental contaminants that damage the membrane, as already mentioned.

Therefore, the crucial question is as follows: what is the extent of this efect with regard to AO and NR? Because the main inducer

Table 1

Calculated values for $[\mathrm{AOO}]_{\mathrm{o}},[\mathrm{NR}]_{\mathrm{o}},\left[\mathrm{AOH}^{+}\right]_{\mathrm{o}}$, and $\left[\mathrm{NRH}^{+}\right]_{\mathrm{o}}$ supposing the addition of $10 \mu \mathrm{M} \mathrm{AO}$ and NR and the accumulation for AO and NR

\begin{tabular}{llllllll}
\hline & \multicolumn{3}{l}{ Neutral red } & & \multicolumn{3}{l}{ Acridine orange } \\
\cline { 2 - 3 } & $R$ & {$[\mathrm{NR}]_{\mathrm{o}}$} & {$\left[\mathrm{NRH}^{+}\right]_{\mathrm{o}}$} & & $R$ & {$[\mathrm{AO}]_{\mathrm{o}}$} & {$\left[\mathrm{AOH}^{+}\right]_{\mathrm{o}}$} \\
\hline $\mathrm{pH}_{\mathrm{i}} 4.0$ & 432 & $1.28 \times 10^{-8}$ & $1.28 \times 10^{-9}$ & & $10^{3.5}$ & $10^{-11.5}$ & $10^{-8.5}$ \\
$\mathrm{pH}_{\mathrm{i}} 5.0$ & 44 & $1.2 \times 10^{-7}$ & $1.2 \times 10^{-8}$ & & $10^{2.5}$ & $10^{-10.5}$ & $10^{-7.5}$ \\
$\mathrm{pH}_{\mathrm{i}} 6.0$ & 5.18 & $2.5 \times 10^{-6}$ & $2.5 \times 10^{-7}$ & & $10^{1.5}$ & $10^{-9.5}$ & $10^{-6.5}$ \\
$\mathrm{pH}_{\mathrm{i}} 7.0$ & 1.29 & $0.3 \times 10^{-5}$ & $0.3 \times 10^{-6}$ & & $10^{0.5}$ & $2.4 \times 10^{-9}$ & $0.4 \times 10^{-5}$ \\
$\mathrm{pH}_{\mathrm{i}} 7.5$ & 1 & $0.4 \times 10^{-5}$ & $0.4 \times 10^{-6}$ & 1 & $5 \times 10^{-9}$ & $0.5 \times 10^{-5}$ \\
\hline
\end{tabular}

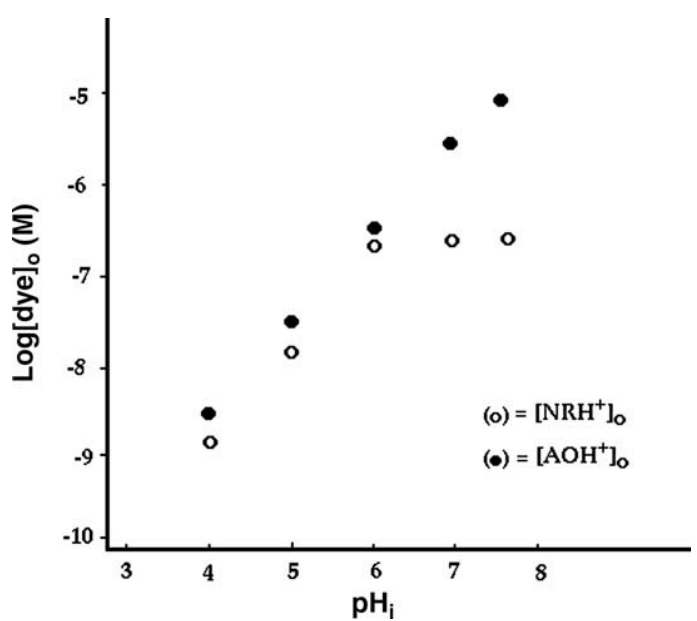

Fig. 3. Visualization of the data in Table 1 reported regarding the concentrations of $\mathrm{AOH}^{+}$( $\mathrm{AO}$ in the protonated form) and $\mathrm{NRH}^{+}$( $\mathrm{NR}$ in the protonated form) in the external medium $\left(\left[\mathrm{AOH}^{+}\right]_{\mathrm{o}}\right.$ and $\left.\left[\mathrm{NRH}^{+}\right]_{\mathrm{o}}\right)$. In the case of $\mathrm{AOH}^{+}$, the external concentration depends on the internal $\mathrm{pH}\left(\mathrm{pH}_{\mathrm{i}}\right)$ between $\mathrm{pH}_{\mathrm{i}} 4.0$ and 7.5. Therefore, AO measures the $\mathrm{pH}_{\mathrm{i}}$ changes in the whole $\mathrm{pH}_{\mathrm{i}}$ range. In the case of $\mathrm{NRH}^{+}$, the response occurs only up to $\mathrm{pH}_{\mathrm{i}} 6.0$. Above this value $\left(\mathrm{pH}_{\mathrm{i}} 6.0-7.5\right)$, the $\mathrm{pH}_{\mathrm{i}}$ changes are not monitored by the dye. Because the $\mathrm{pH}_{\mathrm{i}}$ changes are due to the lysosomal membrane damage induced by toxic compounds, this dye is unable to monitor the effects of toxic compounds when enhancements of $\mathrm{pH}_{\mathrm{i}}$ values above 6.0 are induced. A similar behavior can be visualized if the values of AO and NR in the nonprotonated form are reported $\left([\mathrm{AO}]_{\mathrm{o}}\right.$ and $[\mathrm{NR}]_{\mathrm{o}}$ )

of the protonophore effect is the potential (the transport of the undissociated compound is rapid, as Fig. 2 shows in the case of $\mathrm{AO}$ ), a measurement of the protonophore effect (or the uncoupling effect [22]) in mitochondria is useful at this point, where the internal potential is high at approximately $-200 \mathrm{mV}$.

There are many procedures used to assess the presence of a protonophore in mitochondria. Once it has been verified that the protonophore does not inhibit the stimulated respiratory rate (not shown), the simplest procedure is to measure the stimulation induced by a protonophore in the basal mitochondrial respiration (state 4 mitochondrial respiration [14,22]). Fig. 4A shows the mitochondrial state 4 stimulation induced by FCCP, which is a classical protonophore. Fig. 4B shows that a similar effect is induced by means of $20 \mu \mathrm{M}$ NR. Fig. $4 \mathrm{C}$ shows that no stimulation is obtained with $80 \mu \mathrm{M}$ AO. The behavior of the AO dye in this case confirms the data already reported [14]. This leads us to the conclusion that $\mathrm{NR}$, as in literature [24], is a protonophore, whereas AO is not in analogous conditions. Consequently, AO is "less contaminating" or invasive than NR; that is, the presence of $\mathrm{AO}$ in the biological membrane is less toxic and destructive than that of NR.

\section{Conclusions}

The above-discussed results lead to the following conclusions. First, the analytical calculations indicate that the response of $\mathrm{AO}$ covers the whole $\mathrm{pH}$ range between 4.0 and 7.5, whereas NR is insensitive in the $\mathrm{pH}$ range between 6.0 and 7.5. Second, the experimental measurements indicate that, in similar conditions, AO is not a protonophore, whereas NR has a protonophore effect that is similar to that induced by toxic compounds. These two crucial points, together with the facts that the absorption coefficient $(\varepsilon)$ is 18,000 for $\mathrm{AO}$ and 18,500 for NR (allowing the use of lower concentrations of $A O$ to obtain the same responses as with NR) and that the accumulation of AO is instantaneous (Fig. 2) and no incubation times are necessary (whereas the standard test implies an incubation period of $3 \mathrm{~h}$ in the case of NR [14]), lead us to the conclusion that $\mathrm{AO}$ is preferable to NR for toxicity measurements in 
A

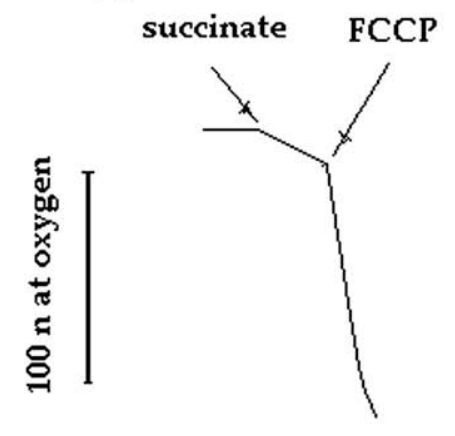

B

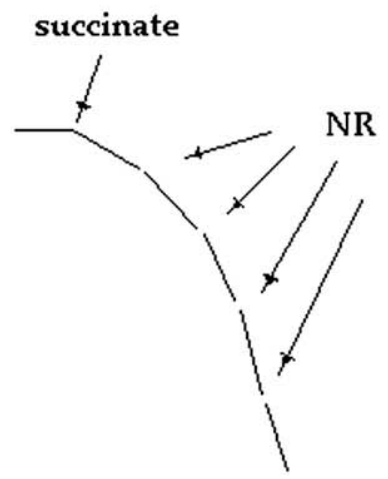

C

\section{succinate}

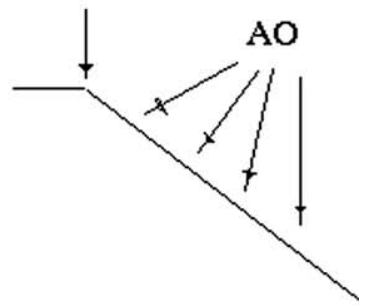

\section{$1 \mathrm{~min}$}

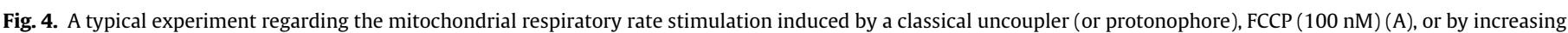

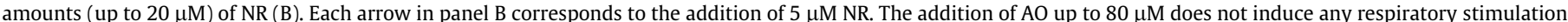

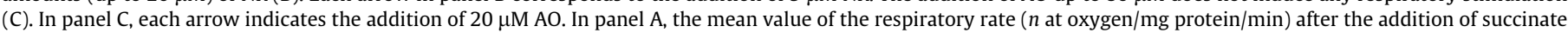

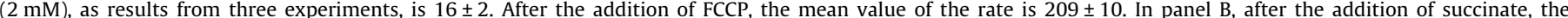

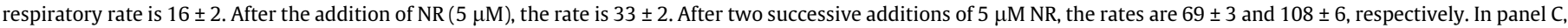
the basal respiration is $16 \pm 2$ and the addition of $A O$ does not induce respiratory rate modifications.

aqueous samples using biological structures such as the mussels used in the standard test procedure.

\section{References}

[1] M. Bragadin, D. Marton, S. Manente, A. Iero, V. Rizzoli, G. Perin, G. Scutari, A bioanalytical method for the monitoring of metal alkyls in solution, Anal. Biochem. 269 (1999) 420-423.

[2] M. Bragadin, R. Piazza, G. Scutari, S. Manente, Mitochondria as biosensors for the monitoring of detergent compounds in solution, Anal. Biochem. 292 (2001) 305-307.

[3] D.M. Lowe, R.K. Pipe, Contaminant induced lysosomal membrane damage in marine mussel digestive cells: An in vitro study, Aquat. Toxicol. 30 (1994) 357-365.

[4] M. Bragadin, P. Dell'Antone, A new "in vitro" toxicity test based on the response to toxic substances in solution of (thawed) beef heart mitochondria Arch. Environ. Contam. Toxicol. 27 (1994) 410-414.

[5] M. Bragadin, G. Perin, S. Manente, A. Iero, G. Scutari, A new procedure for the monitoring of cationic detergents in solution, Environ. Technol. 21 (2000) 1-3.

[6] M. Bragadin, E. Argese, E. Orsega, A simple "in vitro" method for selective detection of the presence of phenols in water using the mitochondrial membrane from rat liver, Environ. Technol. 12 (1991) 777-781.

[7] C. Svendsen, D.J. Spurgeon, P.K. Hankard, J.M. Weeks, A review of lysosomal membrane stability measured by neutral red retention: Is it a workable earthworm biomarker?, Ecotoxicol Environ. Safety 57 (2004) 20-29.

[8] L. Da Ros, F. Meneghetti, C. Nasci, Field application of lysosomal destabilization indices in the mussel Mytilus galloprovincialis: biomonitoring and transplantation in the lagoon of Venice (north-east Italy), Mar. Environ. Res. 54 (2002) 817-822.

[9] E. Mamaca, R.K. Beckmann, S. Torgrimsen, E. Aas, A. Bjornstad, T. Baussant, S.L Floch, The neutral red lysosomal retention assay and Comet assay on haemolymph cells from mussels (Mytilus edulis) and fish (Symphodus melops) exposed to styrene, Aquat. Toxicol. 75 (2005) 191-201.

[10] M.N. Moore, Cytochemical responses of the lysosomal system and NADPHferrihemoprotein reductase in molluscan digestive cells of environmental and experimental exposure to xenobiotics, Mar. Ecol. Prog. 46 (1988) 81-89.
[11] P. Dell'Antone, M. Bragadin, P. Zatta, Anticholinesterasic drugs: Tacrine, but not physostigmine, accumulates in acidic compartments of the cells, Biochim. Biophys. Acta 1270 (1995) 137-141.

[12] M. Bragadin, T. Pozzan, G.F. Azzone, Kinetics of Ca++ carrier in rat liver mitochondria, Biochemistry 18 (1979) 5972-5978.

[13] O.H. Lowry, H.J. Rosenbrough, A.L. Farr, R.J. Randall, Protein measurement with the folin phenol reagent, J. Biol. Chem. 193 (1951) 265-275.

[14] M.S. Mai, W.S. Allison, Inhibition of an oligomycin-sensitive ATPase by cationic dyes, some of which are atypical uncouplers of intact mitochondria, Arch. Biochem. Biophys. 221 (1983) 467-476.

[15] P. Dell'Antone, R. Colonna, G.F. Azzone, The membrane structure studied with cationic dyes: I. The binding of cationic dyes to submitochondrial particles and the question of the polarity of the ion-translocation mechanism, Eur. J. Biochem. 24 (1972) 553-565.

[16] P. Dell'Antone, R. Colonna, G.F. Azzone, The membrane structure studied with cationic dyes: II. Aggregation, metachromatic effects, and pKa shifts, Eur. J. Biochem. 24 (1972) 566-576.

[17] M. Bragadin, D. Marton, S. Manente, A. Toninello, The interaction of tributyllead with lysosomes from rat liver, J. Inorg. Biochem. 83 (2001) 229232.

[18] S. Budavari (Ed.), Merck Index, 12th ed., Merck, Whitehouse Station, NJ, 1989.

[19] I. Mellman, R. Fuchs, H. Helenius, Acidification of the endocytic pathways, Annu. Rev. Biochem. 55 (1986) 663-700.

[20] E.G. Popov, A.G. Mejlumian, J.Y. Gawrilov, Z. Gabbesow, E.Y. Porin, Evalutation of the ability of intact platelets to accumulate acridine orange, Experientia 44 (1988) 616-618.

[21] E. Borenfreund, G.A. Puerner, A simple quantitative procedure using monolayer cultures for cytotoxicity assays (HTD/NR-90), J. Tissue Culture Methods 9 (1984) 7-9.

[22] P. Mitchell, Keilin's respiratory chain concept and its chemiosmotic consequences, Science 286 (1969) 1148-1159.

[23] S. Ohkuma, Y. Moriyama, T. Takano, Electrogenic nature of lysosomal proton pump as revealed with a cyanine dye, J. Biochem. 94 (1983) 1935-1943.

[24] K. Hosoi, G. Soe, T. Katuno, T. Horio, Effects of pH indicators on various activities of chromatophores of Rhodospirillium rubrum, J. Biochem. 78 (1975) 1331-1346. 